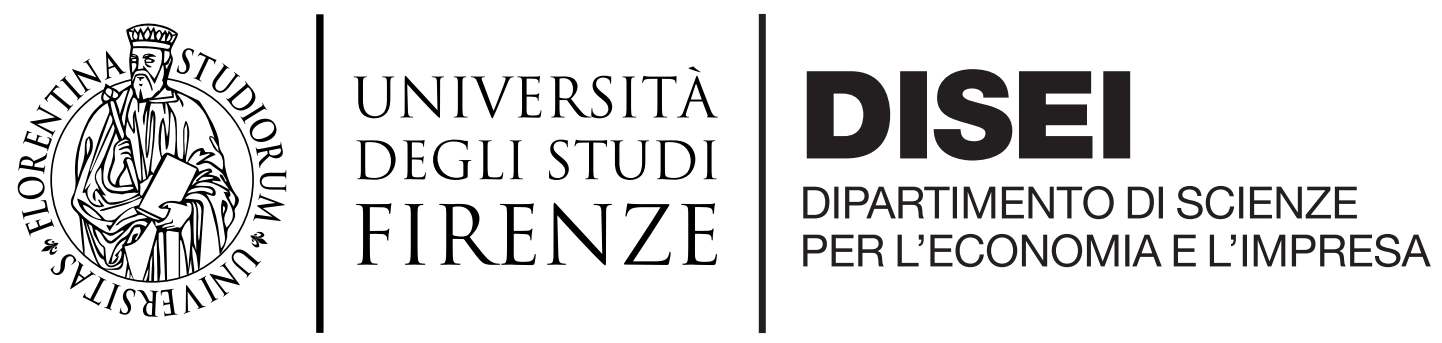

WORKING PAPERS - ECONOMICS

\title{
Technological Foundations for Dynamic Models with Endogenous Entry
}

\author{
FEDERICO ETRO
}

Working PAPER N. 12/2020

DISEI, Università degli Studi di Firenze

Via delle Pandette 9, 50127 Firenze (Italia) www.disei.unifi.it

The findings, interpretations, and conclusions expressed in the working paper series are those of the authors alone. They do not represent the view of Dipartimento di Scienze per l'Economia e l'Impresa 


\title{
Technological Foundations for Dynamic Models with Endogenous Entry
}

\author{
by Federico Etro ${ }^{1}$
}

University of Florence

\begin{abstract}
I explore the technological foundations of dynamic entry models à la BilbiieGhironi-Melitz where the endogenous creation of new inputs can generate either neoclassical business cycle dynamics or long run growth. Under a general CRS technology in labor and intermediate goods produced by monopolistic innovators, substitutability between inputs drives markups and profitability of innovations as functions of the number of firms. Decreasing profitability tends to generate a stable steady state associated with a propagation of shocks fostered by endogenous productivity. The decentralized equilibrium is inefficient and I characterize the optimal policy to fix static and dynamic inefficiencies.
\end{abstract}

Key words: Entry, monopolistic competition, variable markups, technology, business cycle.

JEL Code: E1, E2, E3, F4, L1.

\footnotetext{
${ }^{1}$ I am grateful to Paolo Bertoletti, Florin Bilbiie and two anonymous referees for important comments and to Lilia Cavallari, Andrea Colciago and Lorenza Rossi for discussions on the topic. Correspondence: Federico Etro: Florence School of Economics and Management, Via delle Pandette 32, Florence, 50127. Phone: 055-2759603. Email: federico.etro@unifi.it.
} 


\section{Introduction}

Neoclassical models for the study of the propagation of business cycles are based on investment in capital accumulation that depends on the marginal productivity of capital combined with shocks to exogenous productivity and mechanisms of intertemporal substitution (Kydland and Prescott, 1982). Innovation-based models for the study of long run growth are founded on investment in the creation of new inputs that depends on the (marginal) profitability of R\&D activity and leads to endogenous increase of productivity (Romer, 1987, 1990). Although the aggregate technology for the production of final goods is at the basis of both these major lines of research, the relation between them remains obscure in the macroeconomic literature. A major step to integrate the two approaches and develop a new framework for macroeconomic analysis was made possible by dynamic entry models where endogenous business creation affects business cycle fluctuations (Bilbiie et al., 2012). These models are based on monopolistic competition in the market for final goods where homothetic preferences of consumers generate demand of new consumption goods: in such an environment, entry of new firms and products makes consumers better off and contributes to amplify the propagation of exogenous productivity shocks, but neither affects productivity nor generates long run growth.

In this work I translate dynamic entry models in terms of monopolistic competition in the market for inputs, introduce a general constant returns to scale (CRS) and symmetric technology for the production of final goods which determines the demand of inputs, and show that this can give raise either to a 
neoclassical business cycle mechanism or to an endogenous growth mechanism. What determines the evolution of the economy is the substitutability between intermediate goods in the aggregate technology, which drives pricing and profitability of the producers of inputs. When technology delivers a profitability of innovations that is decreasing in the number of inputs used in production, the destiny of the economy is typically a steady state where new inputs simply replace obsolete ones, as in neoclassical models with decreasing marginal productivity of capital (with a steady state where new capital replaces depreciated capital). This is also the case in which aggregate shocks determine a business cycle propagation analogous to the one of real business cycle models, but amplified by entry that boosts the endogenous productivity. Only when the technological conditions allow for an asymptotically constant (and large enough) profitability of innovations due to independent inputs, the destiny of the economy is a constant growth path fueled by continuous creation of new firms.

I study the dynamics of the deterministic equilibrium system showing that this is saddle-path stable when the economy is dynamically efficient in steady state. However, the equilibrium is inefficient in the short run due markups variable between labor and other inputs and over time, and I derive the optimal taxation that fixes static and dynamic inefficiencies: this requires a positive production subsidy and a dividend tax or subsidy that can vary over the business cycle. All the results are exemplified through two examples that can be used for quantitative investigations, based on technologies featuring a Constant Elasticity of Substitution (CES) aggregator and a generalized linear aggregator 
(Diewert, 1971).

The analysis of dynamic entry models with monopolistic competition in final goods and homothetic preferences is due to Bilbiie et al. (2012). However, in that model and the subsequent applications entry cannot generate long run growth and endogenous productivity. The present analysis of monopolistic competition in inputs under a general CRS technology is based on recent advances in the theory of monopolistic competition in final goods under general microfoundations by Bertoletti and Etro (2016). ${ }^{2}$ Other applications to business cycle analysis with and without endogenous entry are in Etro $(2016,2018)$ and Cavallari and Etro (2020), while related dynamic entry models with oligopolistic competition include work by Jaimovich and Floetotto (2008), Etro and Colciago (2010), Savagar (2017), Dixon and Savagar (2020) and others. An analysis of long run growth with population growth is investigated in Etro (2019) in a model with an exogenous saving rate.

The rest of the work is organized as follows. Section 2 introduces the model and exemplifies its implications with an example. Section 3 analyzes the general model and the dynamics. Section 4 is about optimal taxation. Section 5 concludes.

\footnotetext{
${ }^{2}$ That work was focused on a demand system derived from a representative consumer with general preferences over a discrete number of goods. See also subsequent works by Bertoletti and Etro $(2017,2018)$ on specific classes of preferences, and Parenti et al. (2017) on the case of a continuum of goods.
} 


\section{The model}

I consider a representative agent with the standard preferences:

$$
U=\mathbb{E}\left[\sum_{t=1}^{\infty} \beta^{t-1}\left(\log C_{t}-\frac{v l_{t}^{1+\frac{1}{\varphi}}}{1+\frac{1}{\varphi}}\right)\right]
$$

where $\mathbb{E}[\cdot]$ is the expectations operator at time $t=0, \beta \in(0,1)$ is the discount factor, $C_{t}$ is consumption of the final good, $l_{t}$ is labor supply, $\varphi \geq 0$ is the Frisch elasticity and $v \geq 0$ is a scale parameter for the disutility of labor. Consumers save by investing in a mutual fund that finances the creation of new intermediate goods. Given the return rate $r_{t}$ and the wage $w_{t}$, the standard FOCs for utility maximization are:

$$
l_{t}=\left[\frac{w_{t}}{v C_{t}}\right]^{\varphi} \text { and } \quad \frac{1}{C_{t}}=\beta \mathbb{E}\left\{\frac{1+r_{t+1}}{C_{t+1}}\right\}
$$

The final good is the numeraire of the economy, and is produced by a perfectly competitive sector employing labor in quantity $L_{t}$ and $N_{t}$ intermediate goods in quantity $X_{j t}$ for $j=1,2, \ldots N_{t}$. The intermediate goods are produced by monopolists with a linear technology transforming a unit of final good into a unit of intermediate good. The creation of a firm able to produce a new variety of input requires a fixed investment $\eta$ in units of the final good one period ahead. The gross domestic product (GDP) of this closed economy is given by the output of final goods $Y_{t}$ net of intermediate goods at factor cost $\sum_{j=1}^{N_{t}} X_{j t}$, and is destined to either consumption $C_{t}$ or savings. In each period the number of new firms $N_{t}^{e}$ must satisfy the equality of investment $N_{t}^{e} \eta$ and savings 
according to the resource constraint:

$$
Y_{t}=\sum_{j=1}^{N_{t}} X_{j t}+C_{t}+N_{t}^{e} \eta
$$

Entry of producers of new intermediate goods is endogenous. However, these goods become obsolete in each period with probability $\delta>0$, inducing the exit of their producers. Therefore, the rate of change of the number of firms or intermediate goods follows:

$$
N_{t+1}=N_{t}^{e}+(1-\delta) N_{t}
$$

which drives the dynamics of the economy. ${ }^{3}$

The main novelty of the analysis is a general neoclassical technology for the production of final goods, with the following CRS production function:

$$
Y_{t}=F\left(A_{t} L_{t}, \mathbf{X}_{t}\right)
$$

where $A_{t}$ represents exogenous labor productivity, $\mathbf{X}_{t}$ is the vector of intermediate goods, and the function $F$ is increasing and concave in each input and assumed symmetric in the intermediate goods. ${ }^{4}$

\footnotetext{
${ }^{3}$ The rest of the results would be marginally affected by considering the equation of motion used by Ghironi and Melitz (2005) and the subsequent literature, where depreciation applies also to the new varieties. I adopt a more standard formulation to emphasize similarities with dynamic models of capital accumulation. The model could be also adapted to the use of labor to create new varieties as in Bilbiie et al. (2012) without substantial changes in the results.

${ }^{4}$ More precisely, this can be seen as a reduced form of a symmetric production function defined over an arbitrarily large number of potential intermediate goods, $N_{t}$ of which are provided in positive quantity at time $t$. Relevant properties of symmetric functions are discussed in Feenstra (2003) and Bertoletti and Etro (2016).
} 
The technology used by Romer (1990) to study product creation in a sim-

ilar framework was given by $Y_{t}=\left(A_{t} L_{t}\right)^{1-\alpha} \sum_{j=1}^{N_{t}} X_{j_{t}}^{\alpha}$ with $\alpha \in(0,1)$. Related technologies satisfying additive separability between intermediate goods (Romer, 1987) imply that the demand of each intermediate good is separable from the demand of all the others. This excludes any form of substitutability between these inputs (given the labor input), and is actually the root of the constant growth path obtained by Romer (1990) in a deterministic environment. Postponing the detailed analysis of general technologies to the next Section, here I want to sketch a slight generalization of the Romer model which allows to generate a rather different dynamic behavior and can be used for quantitative applications in business cycle analysis.

\subsection{CES technology}

Consider the following CES technology:

$$
Y_{t}=\left(A_{t} L_{t}\right)^{1-\alpha}\left(\sum_{j=1}^{N_{t}} X_{j t}^{\frac{\theta-1}{\theta}}\right)^{\frac{\theta \alpha}{\theta-1}}
$$

where $\theta>1$ is the elasticity of substitution between intermediate goods. One can easily verify that when $\alpha=1-1 / \theta$ we are back to the Romer case with independent intermediate goods, but for $\alpha<1-1 / \theta$ these inputs are substitutes in the production of final goods, which is the neoclassical case I am interested in. In each period, the competitive sector producing final goods demands intermediate goods and labor according to standard conditions equating their marginal productivity to the prices $p_{i t}$ for the intermediate goods $i$ and to the wage $w_{t}$ for labor. Given this CES technology, each producer of intermediate goods faces 
a demand with a constant elasticity $\theta$ in its price, but this demand depends also on the prices of all the other inputs. Under monopolistic competition, however, each producer tends to ignore the interaction with the other producers and sets the price of its input in every period as a constant markup on the unitary marginal cost:

$$
p_{t}=\frac{\theta}{\theta-1}
$$

This symmetry across producers and over time allows us to recover easily the equilibrium demand of each input as $X\left(N_{t}\right)=\phi N_{t}^{\frac{1-\theta(1-\alpha)}{(\theta-1)(1-\alpha)}} A_{t} L_{t}$ for a given constant $\phi \equiv((\theta-1) \alpha / \theta)^{\frac{1}{1-\alpha}}$. In the Romer case (when $\left.\alpha=1-1 / \theta\right)$, the impact of the number of inputs disappears and the production level grows with the scale of the economy, but when the inputs are substitutable (when $\alpha<1-1 / \theta$ ), a larger number of them is going to reduce the producton of each new input. Since the profits of each producer are given by $\Pi\left(N_{t}\right)=X\left(N_{t}\right) /(\theta-1)$, they must follow the same relation with the number of firms. Endogenous entry of firms implies that in every period the present discounted value of profits must equate the entry cost, and the equilibrating variable is the interest rate, which therefore will follow the same pattern of profits and production:

$$
\frac{\Pi\left(N_{t}\right)}{r_{t}+\delta}=\eta
$$

I can also recover the aggregate output as $Y_{t}=\phi^{\alpha} A_{t} L_{t} N_{t}^{\frac{\alpha}{(\theta-1)(1-\alpha)}}$, which is linear in the number of inputs in the Romer case, but is concave in the general case: substitutability between inputs introduces a sort of decreasing marginal productivity in the number of intermediate goods which is what insures conver- 
gence toward a steady state. And it is standard to verify that the equilibrium wage is a constant fraction of output per capita:

$$
w_{t}=(1-\alpha) \phi^{\alpha} A_{t} N_{t}^{\frac{\alpha}{(\theta-1)(1-\alpha)}}
$$

which is also a function of the number of firms. Combining resource constraint (3) and equation of motion (4) with the equilibrium production levels we obtain the evolution of the stock variable represented by the endogenous number of firms as:

$$
N_{t+1}=\frac{\left(1-\alpha+\frac{\alpha}{\theta}\right) \phi^{\alpha} A_{t} L_{t} N_{t}^{\frac{\alpha}{(\theta-1)(1-\alpha)}}-C_{t}}{\eta}+(1-\delta) N_{t}
$$

and combining interest rate and wage with the behavioral rules (2) we have a complete characterization of the evolution of aggregate consumption, labor and number of firms. In a deterministic environment this produces a constant endogenous growth when $\alpha=1-1 / \theta$ and a saddle-path stable evolution toward a steady state when $\alpha<1-1 / \theta .^{5}$ In a stochastic environment, the last case generates a business cycle dynamics that is magnified by the endogenous creation of inputs which affects the effective productivity.

\subsection{Other technologies}

The CES example is by no means unique for its implications. As an illustration of a more general class of production functions nested in (5), let us consider:

$$
Y_{t}=\left(A_{t} L_{t}\right)^{1-\alpha} \Psi\left(\mathbf{X}_{t}\right)^{\alpha}
$$

\footnotetext{
${ }^{5}$ It is interesting to notice that in the case of a stable saddle-path, the growth effects of market size expansions would be sterilized by firm's entry and a constant population growth would drive a constant endogenous growth rate (as in Jones, 1995).
} 
where $\Psi\left(\mathbf{X}_{t}\right)$ is a linearly homogeneous aggregator. The case of the CES aggregator emerges when:

$$
\Psi\left(\mathbf{X}_{t}\right)=\left(\sum_{j=1}^{N_{t}} X_{j t}^{\frac{\theta-1}{\theta}}\right)^{\frac{\theta}{\theta-1}}
$$

Another useful example is based on a generalized linear aggregator à la Diewert (1971) as: ${ }^{6}$

$$
\Psi\left(\mathbf{X}_{t}\right)=\sum_{j=1}^{N_{t}}\left(\gamma X_{j t}+\sum_{k \neq j}^{N_{t}} \sqrt{X_{j t} X_{k t}}\right)
$$

with $\gamma>0$. I will return to these two examples repeatedly, but the general analysis of the next Section will apply to any CRS technology represented by (5). Other useful examples can be based on implicit additivity (Hanoch, 1975), ${ }^{7}$ generalized separability (Pollak, 1972), ${ }^{8}$ translog specifications (Feenstra, 2003) and others taking into account the impact of the number of inputs on the functional form. One can also consider production externalities that are positively related to the number of intermediate goods since they preserve the CRS of the technology.

${ }^{6}$ I am thankful to Paolo Bertoletti for pointing out this example. See Bertoletti and Etro (2016) for monopolistic competition in final goods under a generalized linear preference aggregator.

${ }^{7} \mathrm{~A}$ production function à la Kimball (1995) implicitly defined by:

$$
1=\sum_{j=1}^{N_{t}} \tilde{F}\left(A_{t} L_{t} / Y_{t}, X_{j t} / Y_{t}\right)
$$

satisfies CRS and delivers a demand of each intermediate good that depends on the same aggregate production and, therefore, on the quantity of the other inputs.

${ }^{8}$ See Matsuyama and Ushchev (2017) and Bertoletti and Etro (2018) for further applications. 


\section{General analysis}

In this Section I solve for the equilibrium of the general model and analyze its dynamic behavior. It is convenient to analyze the model defining variables per effective worker, denoted with lower case letters. Exploiting CRS, the general production function (5) can be re-expressed in intensive form as $Y_{t}=A_{t} L_{t} f\left(\mathbf{x}_{t}\right)$, where $x_{i t}=X_{i t} / A_{t} L_{t}$ is the production level of good $i$ per effective worker and $f(\mathbf{x}) \equiv F(1, \mathbf{x})$ is a symmetric function with $f(\mathbf{u} 0)=0$, where $\mathbf{u}$ is a unit vector, $f_{i}(\mathbf{x}) \equiv \partial f(\mathbf{x}) / \partial x_{i}>0$ and $f_{i i}(\mathbf{x}) \equiv \partial^{2} f(\mathbf{x}) / \partial x_{i}^{2}<0 . \quad$ I also assume that the function under symmetric inputs $f(\mathbf{u} x)$ is differentiable and increasing in the number of goods $N$ for any constant $x$, and that the (production) gains from variety are large enough that $f_{N}(\mathbf{u} x)>x .^{9}$

\subsection{Monopolistic competition and input prices}

The inverse demand of each intermediate good $i$ in period $t$ satisfies $p_{i t}=f_{i}\left(\mathbf{x}_{t}\right)$, which is decreasing in $x_{i t}$, and changes with the production level of the other intermediate goods depending on the sign of $f_{i j}(\mathbf{x}) \equiv \partial^{2} f(\mathbf{x}) / \partial x_{i} \partial x_{j}$. In particular, taking as given the labor input, the intermediate goods are independent if $f_{i j}(\mathbf{x})=0$, as under the separability assumed by Romer $(1987,1990)$, but they are substitutes if $f_{i j}(\mathbf{x})<0$, which holds for instance in the CES and Diewert examples for a small enough $\alpha$. The associated variable profits of firm $i$ in period $t$ are $\Pi_{i t}=\pi_{i t} A_{t} L_{t}$, where the profits per effective worker $\pi_{i t}$ are

\footnotetext{
${ }^{9}$ For instance, the Romer case implies $f(\mathbf{u} x)=N x^{\alpha}$, the CES case implies $f(\mathbf{u} x)=$ $N^{\frac{\alpha \theta}{\theta-1}} x^{\alpha}$ and the Diewert case implies $f(\mathbf{u} x)=[N(N+\gamma-1)]^{\alpha} x^{\alpha}$.
} 
defined as:

$$
\pi_{i t}=f_{i}\left(\mathbf{x}_{t}\right) x_{i t}-x_{i t}
$$

These are maximized taking the labor force as given and chosing the production level per effective worker $x_{i t}$ under monopolistic competition (Dixit and Stiglitz, 1977). Symmetry implies that the relevant demand elasticity $\epsilon\left(N_{t}, x_{t}\right)$ depends in each period either on the number of inputs $N_{t}$ or the equilibrium production per effective worker $x_{t}$. Bertoletti and Etro (2016) have shown that the equilibrium elasticity is the symmetric version of the Morishima elasticity of complementarity between inputs, implying prices:

$$
p_{t}=\frac{1}{1-\epsilon\left(N_{t}, x_{t}\right)} \quad \text { with } \epsilon(N, x)=\frac{f_{j i}(\mathbf{u} x) x-f_{i i}(\mathbf{u} x) x}{f_{i}(\mathbf{u} x)}
$$

This allows one to compute price rules for any technology. For instance, in the Romer case the monopolistic price is constant at $p=\frac{1}{\alpha}$. Also the CES example delivers a constant price $p=\frac{\theta}{\theta-1}$ in spite of substitutability. Instead, the Diewert example generates a price $p_{t}=2 \frac{1+(\gamma-1) / N_{t}}{1+2(\gamma-1) / N_{t}}$, which is constant only for $\gamma=1$ and otherwise can be either decreasing or increasing in the number of firms: markups are countercyclical for $\gamma<1$ and pro-cyclical for $\gamma>1$. Finally, departing from a homogenous aggregator of the intermediate goods, the price would depend also on the scale of production $x .^{10}$

\footnotetext{
${ }^{10}$ The mentioned implicit additivity delivers the following elasticity:

$$
\epsilon(N, x)=-\frac{\tilde{F}_{X X}(1 / y, x / y) x}{\tilde{F}_{X}(1 / y, x / y) y}
$$

where the aggregator $y$ is output per effective worker and satisfies $1=N \tilde{F}(1 / y, x / y)$, which clarifies how the price depends on both scale of production $x$ and number of goods $N$. Explicit additivity delivers an elasticity that depends on $x$ only (Romer, 1987).
} 
To determine the equilibrium production of each intermediate good for a given number of firms, I use the symmetric demand system $p_{t}=f_{i}\left(\mathbf{u} x_{t}\right)$ and (9) to obtain the following equilibrium condition:

$$
f_{i}\left(\mathbf{u} x_{t}\right)-f_{j i}\left(\mathbf{u} x_{t}\right) x_{t}+f_{i i}\left(\mathbf{u} x_{t}\right) x_{t}=1
$$

This condition implicitly defines the production of each input per effective worker $x_{t} \equiv x\left(N_{t}\right)$ as a function of the number of firms only. I assume this function to be unique and twice differentiable. It is actually a constant when $f(\mathbf{x})$ is separable in the inputs (Romer, 1987), since the left hand side of (10) is independent from $N$ : for instance, in the Romer (1990) case the production per effective worker $x=\alpha^{\frac{2}{1-\alpha}}$ remains constant. Otherwise, the production depends on the number of firms in an ambiguous way due to the high order derivatives obtained differentiating (10). The CES example implies $x(N)=\phi N^{\tilde{\alpha}-1}$ with $\tilde{\alpha}=\frac{\alpha}{(\theta-1)(1-\alpha)}$, and this production level is always decreasing in the number of firms for $\alpha<\frac{\theta-1}{\theta}$. The Diewert example has ambiguous comparative statics in general, but the simple case where $\gamma=1$ delivers the equilibrium production $x(N)=(\alpha / 2)^{1+\tilde{\alpha}} N^{\tilde{\alpha}-1}$ with $\tilde{\alpha}=\frac{\alpha}{1-\alpha}$, that is decreasing in the number of firms for $\alpha<1 / 2$, which insures input substitutability. ${ }^{11}$

Since the equilibrium elasticity $\epsilon(N, x(N))$ is entirely determined by the number of firms, also markups and profits depend only on the stock variable of the economy represented by the number of firms. Notice that the profits of the marginal firm active in the market are crucial for the entry analysis, but

\footnotetext{
${ }^{11}$ In the general case $x(N)=\frac{\left(\frac{\alpha}{2}[N+2(\gamma-1)]\right)^{\frac{1}{1-\alpha}}}{N(N+\gamma-1)}$ is decreasing in the number of firms for low enough $\alpha$ :
} 
symmetry implies that all firms make the same profits. The profit function per effective worker is therefore:

$$
\pi\left(N_{t}\right)=\frac{\epsilon\left(N_{t}, x\left(N_{t}\right)\right) x\left(N_{t}\right)}{1-\epsilon\left(N_{t}, x\left(N_{t}\right)\right)}
$$

and I assume that it is non-increasing to have a meaningful free entry equilibrium: a sufficient condition for this is that both production $x$ and the elasticity $\epsilon$ are non-increasing in the number of firms. The Romer case delivers constant profits, while the profits for the CES case and the Diewert case are both decreasing when the intermediate goods are substitutable enough.

The present discounted value of a new firm created at time $t$ can be expressed recursively as:

$$
V_{t}=\frac{\pi\left(N_{t+1}\right) A_{t+1} L_{t+1}+(1-\delta) V_{t+1}}{1+r_{t+1}}
$$

and free entry in the market for innovation in each period constraints the return rate and the number of firms such that this value equals the fixed entry cost. This implies the equilibrium return rate:

$$
r_{t}=\frac{\pi\left(N_{t}\right) A_{t} L_{t}}{\eta}-\delta
$$

which follows the pattern of profitability of the entrants.

In the final goods' sector, firms demand labor until its marginal productivity equates the wage insuring zero profits with $w_{t} L_{t}=A_{t} L_{t}\left[f\left(\mathbf{u} x_{t}\right)-N_{t} x_{t} f_{i}\left(\mathbf{u} x_{t}\right)\right]$. Using the equilibrium production of intermediate goods, I can finally express the wage per effective worker as a function of the number of firms:

$$
w\left(N_{t}\right)=f\left(\mathbf{u} x\left(N_{t}\right)\right)-\frac{N_{t} x\left(N_{t}\right)}{1-\epsilon\left(N_{t}, x\left(N_{t}\right)\right)}
$$


and aggregate output as $Y_{t}=A_{t} L_{t} f\left(\mathbf{u} x\left(N_{t}\right)\right)$, where $f\left(\mathbf{u} x\left(N_{t}\right)\right)$ is an equilibrium relation between the output per effective worker and the number of inputs. Finally, it is also convenient to express the GDP per effective worker as:

$$
z\left(N_{t}\right)=f\left(\mathbf{u} x\left(N_{t}\right)\right)-N_{t} x\left(N_{t}\right)
$$

which must correspond to the sum of wage and total profits per effective worker, and is assumed increasing and concave in the number of inputs. This holds in our CES and Diewert examples.

\subsection{General equilibrium}

I can now derive the general equilibrium dynamics for $\left(N_{t}, C_{t}, L_{t}\right)$. The equation of motion for the number of firms (4), using the resource constraint (3) and the net output (14), becomes:

$$
N_{t+1}=\frac{A_{t} L_{t} z\left(N_{t}\right)-C_{t}}{\eta}+(1-\delta) N_{t}
$$

The labor market equilibrium, using the labor supply in (2) and the labor demand satisfying the wage in (13), implies $L_{t}=l_{t}$ satisfying:

$$
L_{t}=\left[\frac{w\left(N_{t}\right) A_{t}}{v C_{t}}\right]^{\varphi}
$$

Finally, consumption follows the Euler equation in (2) with the interest rate given by the free entry condition (12), which provides:

$$
\frac{1}{C_{t}}=\beta \mathbb{E}\left\{\frac{(1-\delta) \eta+\pi\left(N_{t+1}\right) A_{t+1} L_{t+1}}{\eta C_{t+1}}\right\}
$$

Under our assumptions, the dynamics of this system resemble those of an RBC model (where the stock of capital is replaced by the number of firms) 
when net output and wages increase in the number of firms while profitability decreases with them. One can also interpret $A_{t} f\left(\mathbf{u} x\left(N_{t}\right)\right)$ as the effective productivity which is endogenously augmented by investment. Accordingly, the impact of a positive shock is amplified by the increased productivity. In case of a shock to exogenous productivity $A_{t}$, this generates an investment in business creation which endogenously increases productivity and magnifies the propagation of the shock.

\subsection{Dynamics}

It is useful to consider the dynamics of the deterministic environment obtained from the system (15)-(17) after assuming constant productivity and labor force and defining the relative market size as $S \equiv A L / \eta$. For instance, in our two examples of a CES and Diewert technology, the equibrium systems can be represented as follows:

$$
\begin{aligned}
& N_{t+1}=\tilde{z} S N_{t}^{\tilde{\alpha}}-C_{t} / \eta+(1-\delta) N_{t} \\
& C_{t+1}=\beta\left\{1-\delta+\tilde{\pi} S N_{t+1}^{\tilde{\alpha}-1}\right\} C_{t}
\end{aligned}
$$

where $\tilde{\alpha} \in[0,1]$ and the parameters $\tilde{z}$ and $\tilde{\pi}$ depend on the specification. ${ }^{12}$ In either case, when $\tilde{\alpha}=1$ this system gives raise to a constant growth rate for the

\footnotetext{
${ }^{12}$ In the CES example one can compute $\tilde{\alpha}=\frac{\alpha}{(\theta-1)(1-\alpha)}, \tilde{z}=\left(1-\alpha+\frac{\alpha}{\theta}\right) \phi^{\alpha}$ and $\tilde{\pi}=\frac{\phi}{\theta-1}$, and in the Diewert example with $\gamma=1$ one can compute $\tilde{\alpha}=\frac{\alpha}{1-\alpha}, \tilde{z}=\frac{1}{2}\left(\frac{\alpha}{2}\right)^{\frac{\alpha}{1-\alpha}}$, and $\tilde{\pi}=\frac{1}{2}\left(\frac{\alpha}{2}\right)^{\frac{1}{1-\alpha}}$. The CES example nests the Romer (1990) model with constant growth when $\alpha=1-1 / \theta$, and provides a stable saddle-path converging to a steady state for any $\alpha<1-1 / \theta$. The Diewert example provides constant growth when $\alpha=1 / 2$ (so that $\tilde{\pi}=1 / 32$ ) and a stable saddle-path for $\alpha<1 / 2$.
} 
number of firms $g=\beta S \tilde{\pi}-[1-\beta(1-\delta)]$ if this is positive, and when $\tilde{\alpha}<1$ it generates a stable saddle-path converging to the steady state number of firms $N^{*}=\left[\frac{\beta \tilde{\pi} S}{1-\beta(1-\delta)}\right]^{\frac{1}{1-\tilde{\alpha}}}$.

I will now show that these are qualitatively the same two outcomes that can emerge in the general model. When a technology implies $\pi(\infty) S>1 / \beta-1+\delta$, while the number of firms increases the Euler equation implies that the economy approaches the constant rate of long run growth:

$$
g=\beta S \pi(\infty)-[1-\beta(1-\delta)]
$$

This applies to examples with a constant profitability à la Romer (1990) where the economy remains always on a constant growth path. It also applies to more general cases where profitability is only asymptotically constant and the growth rate declines gradually toward its long run level.

In the alternative case where $\pi(\infty) S<1 / \beta-1+\delta$, the monotonicity of profits implies a unique steady state which satisfies:

$$
\pi\left(N^{*}\right)=\frac{1-\beta(1-\delta)}{\beta S}
$$

and implies a number of firms increasing in the discount factor $\beta$ and in the market size $S$, and decreasing in the exit rate $\delta$, while the consumption level in steady state becomes:

$$
C^{*}=\eta\left[z\left(N^{*}\right) S-\delta N^{*}\right]
$$

The process of business creation is dynamically efficient if the steady state does not feature more firms than what maximizes consumption in the long run, that is, if $z^{\prime}\left(N^{*}\right) S \geq \delta$. This requires conditions on high order derivatives of the 
equilibrium production function without immediate interpretation, but it is easy to verify that dynamic efficiency always holds in our CES and Diewert examples above. The important point is that saddle-path stability is insured in general by dynamic efficiency. To verify this, notice that the Jacobian of the equilibrium system for number of firms and consumption is:

$$
J=\left[\begin{array}{cc}
S z^{\prime}\left(N^{*}\right)+1-\delta & -1 / \eta \\
\beta S \pi^{\prime}\left(N^{*}\right) C^{*}\left[S z^{\prime}\left(N^{*}\right)+1-\delta\right] & 1-\beta S \pi^{\prime}\left(N^{*}\right) C^{*} / \eta
\end{array}\right]
$$

with $\operatorname{tr} J>2$ and $\operatorname{det} J>1$ for $z^{\prime}\left(N^{*}\right) S \geq \delta$, which insures the existence of two real positive eigenvalues one of which is larger than unity. However, beyond this, I cannot exclude dynamic inefficiency or more complex dynamics. ${ }^{13}$

I conclude by mentioning the main difference with the dynamics of the model of Bilbiie et al. (2012), where net entry is affected by the number of firms through its impact on the consumption aggregator and not on the production function, while profitability decreases due to the lower consumption of each good when more goods are available. Moreover, departing from CES intratemporal preferences, markup variability over time affects the mechanisms of intertemporal substitution. This excludes mechanisms based on endogenous growth and productivity.

\footnotetext{
${ }^{13}$ At the very least, the possibility of a technology featuring production externalities in the number of inputs allows for complex dynamics.
} 


\section{Market inefficiencies and optimal taxation}

Contrary to what happens in the standard RBC model, the decentralized equilibrium of this and similar models is suboptimal due to imperfect competition (see Etro, 2018, and Bilbiie et al., 2019, for models with monopolistic competition in final goods and endogenous entry). ${ }^{14}$ In our environment, a social planner would solve the problem of maximizing utility (1) with respect to $N_{t+1}$, $C_{t}, L_{t}$ and $\mathbf{X}_{t}$ subject to the constraints (3), (4) and (5). After imposing symmetry on the production of inputs this problem simplifies to:

$\max _{N_{t+1}, L_{t}, x_{t}} \mathbb{E}\left[\sum_{t=1}^{\infty} \beta^{t-1}\left\{\log \left[A_{t} L_{t}\left[f\left(\mathbf{u} x_{t}\right)-N_{t} x_{t}\right]-\eta N_{t+1}+(1-\delta) \eta N_{t}\right]-\frac{v L_{t}^{1+\frac{1}{\varphi}}}{1+\frac{1}{\varphi}}\right\}\right]$

The FOCs are respectively:

$$
\begin{gathered}
\frac{1}{C_{t}}=\beta \mathbb{E}\left\{\frac{(1-\delta) \eta+\left[f_{N}\left(\mathbf{u} x_{t+1}\right)-x_{t+1}\right] A_{t+1} L_{t+1}}{\eta C_{t+1}}\right\} \\
L_{t}=\left\{\frac{A_{t}\left[f\left(\mathbf{u} x_{t}\right)-N_{t} x_{t}\right]}{v C_{t}}\right\}^{\varphi} \\
\sum_{j=1}^{N_{t}} f_{j}\left(\mathbf{u} x_{t}\right)=N_{t}
\end{gathered}
$$

The latter is equivalent to $f_{i}\left(\mathbf{u} x_{t}\right)=1$, and therefore to marginal cost pricing for all goods, and implies a production depending on the number of inputs $x_{t} \equiv x^{o}\left(N_{t}\right),{ }^{15}$ which is above the equilibrium production due to the absence of

\footnotetext{
${ }^{14}$ See also Lewis and Winkler (2015).

${ }^{15}$ The Romer (1990) case provides a constant $x^{o}=\alpha^{\frac{1}{1-\alpha}}$ of the optimal production, but the more general CES case implies $x^{o}(N)=\alpha^{\frac{1}{1-\alpha}} N^{\tilde{\alpha}-1}$, and the Diewert case with $\gamma=1$ implies $x^{o}(N)=\alpha^{\frac{1}{1-\alpha}} N^{\frac{1}{1-\alpha}-2}$.
} 
a markup. Given this, the remaining optimality conditions become: ${ }^{16}$

$$
\begin{gathered}
N_{t+1}=\frac{A_{t} L_{t}\left[f\left(\mathbf{u} x^{o}\left(N_{t}\right)\right)-N_{t} x^{o}\left(N_{t}\right)\right]-C_{t}}{\eta}+(1-\delta) N_{t} \\
L_{t}=\left\{\frac{A_{t}\left[f\left(\mathbf{u} x^{o}\left(N_{t}\right)\right)-N_{t} x^{o}\left(N_{t}\right)\right]}{v C_{t}}\right\}^{\varphi} \\
\frac{1}{C_{t}}=\beta \mathbb{E}\left\{\frac{(1-\delta) \eta+\left[f_{N}\left(\mathbf{u} x^{o}\left(N_{t+1}\right)\right)-x^{o}\left(N_{t+1}\right)\right] A_{t+1} L_{t+1}}{\eta C_{t+1}}\right\}
\end{gathered}
$$

As in other models with endogenous entry (Bilbiie et al., 2019), the decentralized economy features 1) a static distortion, due to positive markups on intermediate goods and not on labor, which delivers a suboptimal production of inputs, and 2) a dynamic distortion, due to markup and profit variability over time, which delivers a suboptimal investment in R\&D. The optimal taxation would require two variable tax rates to fix the problem. Introducing a production subsidy $s_{t}$ on the sales of each firm and a dividend tax $\tau_{t}$ turns profits into $\pi_{i t}=\left[p_{i t}\left(1+s_{t}\right)-1\right] x_{i t}\left(1-\tau_{t}\right)$ and it is easy to verify that the optimal tax rates satisfy:

$$
\begin{gathered}
s_{t}=\frac{\epsilon\left(N_{t}, x^{o}\left(N_{t}\right)\right)}{1-\epsilon\left(N_{t}, x^{o}\left(N_{t}\right)\right)}>0 \\
\tau_{t}=\frac{1}{\epsilon\left(N_{t}, x^{o}\left(N_{t}\right)\right)}\left[1-\frac{f_{N}\left(\mathbf{u} x^{o}\left(N_{t}\right)\right)\left[1-\epsilon\left(N_{t}, x^{o}\left(N_{t}\right)\right)\right]}{x^{o}\left(N_{t}\right)}\right]
\end{gathered}
$$

When the markups are countercyclical the optimal production subsidy is also countercyclical, but the cyclical properties of the dividend tax are more complex, and the same sign of this tax is uncertain, since the decentralized equilibrium may involve either excess or insufficient entry and therefore require either a

\footnotetext{
${ }^{16}$ Notice that under our assumption on the gains from variety $\left(f_{N}(\mathbf{u} x)>x\right)$ the optimal labor supply and GDP increase with the number of firms.
} 
tax or a subsidy on entry. The case of a CES technology (including the "plain vanilla" Romer case) provides optimal taxes:

$$
s_{t}=\frac{1}{\theta-1} \quad \text { and } \quad \tau_{t}=0
$$

In this case, a constant production subsidy is enough to restore optimality because the equilibrium markups are already optimally constant over time and an appropriate constant wedge fixes the static inefficiency. Instead, the general case of a Diewert technology provides the optimal taxes:

$$
s_{t}=\frac{N_{t}}{N_{t}+2(\gamma-1)} \quad \text { and } \quad \tau_{t}=\frac{1-\gamma}{N_{t}+2(\gamma-1)}
$$

to fix both the static and dynamic distortions. Both of them are countercyclical, and the optimal dividend tax is positive (negative) only when $\gamma<(>) 1$.

\section{Conclusion}

I have presented a flexible price DSGE model with a general CRS technology in intermediate goods and labor for the study of business cycle with endogenous productivity. Under substitutability between inputs, the profitability of innovation tends to decrease with the number of inputs, generating convergence to a steady state. Augmented with aggregate shocks, the model can generate a richer amplification mechanism than a basic neoclassical model without capital because a positive temporary shock makes inputs more productive and incentivizes investment and labor supply. While my purpose was methodological, a quantitative analysis is a priority: the framework could be also used for further 
extensions with heterogeneous inputs, trade, price frictions in final goods, imperfections in the credit market à la Bernanke-Gertler, and in the labor market à la Diamond-Mortensen-Pissarides. ${ }^{17}$

\footnotetext{
${ }^{17}$ See Poutineau and Vermandel (2015) and Colciago and Rossi (2015) for related applications with endogenous entry.
} 


\section{References}

Bertoletti, Paolo and Federico Etro, 2016, Preferences, Entry and Market Structure, The RAND Journal of Economics, 47, 4, 792-821.

Bertoletti, Paolo and Federico Etro, 2017, Monopolistic Competition when Income Matters, The Economic Journal, 127, 603, 1217-43.

Bertoletti, Paolo and Federico Etro, 2018, Monopolistic Competition with GAS Preferences, Oxford Economic Papers, in press.

Bilbiie, Florin, Fabio Ghironi and Marc Melitz, 2012, Endogenous Entry, Product Variety, and Business Cycles, The Journal of Political Economy, 120, 2, $304-45$.

Bilbiie, Florin, Fabio Ghironi and Marc Melitz, 2019, Monopoly Power and Endogenous Product Variety: Distortions and Remedies, American Economic Journal: Macroeconomics, 11, 4, 140-74.

Cavallari, Lilia and Federico Etro, 2020, Demand, Markups and the Business Cycle, European Economic Review, 127, 103471.

Colciago, Andrea and Lorenza Rossi, 2015, Firm Dynamics, Endogenous Markups, And The Labor Share Of Income, Macroeconomic Dynamics, 19, 6, 1309-31.

Diewert, Walter Erwin, 1971, An Application of the Shephard Duality Theorem: A Generalized Leontief Production Function, Journal of Political Economy, $79,3,481-507$

Dixit, Avinash and Joseph Stiglitz, 1977, Monopolistic Competition and Optimum Product Diversity, The American Economic Review, 67, 297-308.

Dixon, Huw and Anthony Savagar, 2020, Firm Entry, Excess Capacity and 
Aggregate Productivity, European Economic Review, 121, C.

Etro, Federico, 2016, The Ramsey Model with Monopolistic Competition and General Preferences, Economics Letters, 145, 141-44.

Etro, Federico, 2018, Macroeconomics with Endogenous Markups and Optimal Taxation, Southern Economic Journal, 85, 2, 378-406.

Etro, Federico, 2019, The Romer Model with Monopolistic Competition and General Technologies, Economics Letters, 181, 1-6.

Etro, Federico and Andrea Colciago, 2010, Endogenous Market Structures and the Business Cycle, The Economic Journal, 120, 1201-34

Feenstra, Robert, 2003, A Homothetic Utility Function for Monopolistic Competition Models without Constant Price Elasticity, Economics Letters, 78, 1, $79-86$

Ghironi, Fabio and Marc Melitz, 2005, International Trade and Macroeconomic Dynamics with Heterogenous Firms, Quarterly Journal of Economics, 120, 865-915.

Hanoch, Giona, 1975, Production and Demand Models with Direct or Indirect Implicit Additivity, Econometrica, 43, 3, 395-419.

Jaimovich, Nir and Max Floetotto, 2008, Firms Dynamics, Markups Variations and the Business Cycle, Journal of Monetary Economics, 55, 7, 1238-1252.

Jones, Charles, 1995, R\&D-based Models of Economic Growth, Journal of Political Economy, 103, 4, 759-84.

Kimball, Miles, 1995, The Quantitative Analytics of the Basic Neomonetarist Model, Journal of Money, Credit and Banking, 27, 1241-77 
Kydland, Finn and Edward Prescott, 1982, Time to Build and Aggregate Fluctuations, Econometrica, 50, 6, 1345-70.

Lewis, Vivien and Roland Winkler, 2015, Product Diversity, Demand Structures and Optimal Taxation, Economic Inquiry, 53, 2, 979-1003.

Matsuyama, Kiminori and Philip Ushchev, 2017, Beyond CES: Three Alternative Classes of Flexible Homothetic Demand Systems, CEPR DP12210.

Pollak, Robert, 1972, Generalized Separability, Econometrica, 40, 3, 431-53.

Parenti, Mathieu, Philip Ushchev and Jean-Francois Thisse, 2017, Toward a Theory of Monopolistic Competition, Journal of Economic Theory, 167 (C), 86-115.

Poutineau, Jean-Christophe and Gauthier Vermandel, 2015, Financial Frictions and the Extensive Margin of Activity, Research in Economics, 69, 4, 525-54.

Romer, Paul, 1987, Growth based on Increasing Returns due to Specialization, The American Economic Review, 77, 2, 56-62.

Romer, Paul, 1990, Endogenous Technological Change, The Journal of Political Economy, 98, 5, S71-102.

Savagar, Anthony, 2017, Firm Dynamics, Dynamic Reallocation, Variable Markups, and Productivity Behaviour, mimeo, University of Kent. 